\title{
To bypass or stent? The changing rules of an advancing game
}

\author{
Saswata Deb, MD, and Stephen E. Fremes, MD
}

\section{See related article on pages e5-23.}

Coronary artery bypass grafting surgery (CABG) and percutaneous coronary intervention (PCI) are among the most common medical procedures performed in the United States. ${ }^{1}$ Although in the past decade, significant advances have been made in both of these procedures, and numerous studies published about them, the question of whether, and which one of these modes of coronary revascularization should be offered to any individual patient, and diabetic patients in particular, remains a matter of ongoing debate. ${ }^{2}$ The relative benefit of CABG versus PCI in diabetics was first identified in the Bypass Angioplasty Revascularization Investigation (BARI) study, which showed that CABG was associated with improved 10-year survival compared with balloon angioplasty. $^{3}$ In the past few years, however, many landmark studies have been published, ${ }^{4,5}$ prompting a 2014 update $^{6}$ of the 2012 revascularization guidelines.

The 2 major updates (Table 4 of the update article ${ }^{6}$ ) regarding PCI and CABG are: (1) the change to Class I, Level B evidence, rather than the previous Class IIa, Level $\mathrm{B}$ evidence, for recommendation of $\mathrm{CABG}$ to improve survival in patients with diabetes mellitus and multivessel disease; and (2) a new recommendation for a heart-team approach for patients with complex multivessel disease and diabetes mellitus (Class I, Level C). ${ }^{6}$

The major driving forces for the guideline updates are the subsequent publications of the FREEDOM (Future REvascularization Evaluation in Patients with Diabetes Mellitus: Optimal Management of Multivessel Disease) trial, in 2012, ${ }^{4}$ along with the 5-year results of the SYNTAX (SYNergy Between Percutaneous Coronary Intervention with TAXus and Cardiac Surgery), trial in $2013,{ }^{5}$ stratified according to diabetic status. ${ }^{8}$ SYNTAX, the large $(n=1800$; 85 centers) trial, was the first to randomize CABG and PCI in advanced coronary disease. ${ }^{5}$ In addition to introducing

\footnotetext{
From the Schulich Heart Centre, Sunnybrook Health Sciences Centre, University of Toronto, and the Toronto Ontario Institute of Health Policy Management and Evaluation, University of Toronto, Toronto, Ontario, Canada.

Disclosures: Authors have nothing to disclose with regard to commercial support.

Received for publication Nov 30, 2014; accepted for publication Dec 1, 2014; available ahead of print Jan 10, 2015.

Address for reprints: Stephen E. Fremes, MD, Bernard S. Goldman Chair in Cardiovascular Surgery, University of Toronto, Schulich Heart Centre, Sunnybrook Health Sciences Centre, 2075 Bayview Ave, Room H405, Toronto, ON, Canada M4N 3M5 (E-mail: stephen.fremes@sunnybrook.ca).

J Thorac Cardiovasc Surg 2015;149:679-81

$0022-5223 / \$ 36.00$

Copyright (c) 2015 by The American Association for Thoracic Surgery http://dx.doi.org/10.1016/j.jtcvs.2014.12.002
}

the SYNTAX score, that study demonstrated the important influence of coronary anatomy objectively, through comparative quantified analysis. The 5-year diabetic substudy of SYNTAX showed that CABG, relative to PCI, was associated with significantly lower major adverse cardiac and cerebrovascular events.

The FREEDOM trial ${ }^{4}$ is the largest $(\mathrm{n}=1900: 140$ centers) randomized trial to date comparing CABG to PCI in diabetics with multivessel disease. Reported results from that study were that $\mathrm{CABG}$ is superior to PCI with respect to the primary outcome of all-cause mortality, non-fatal myocardial infarctions, or non-fatal stroke at 5 years, across all levels of the SYNTAX score; however, CABG was associated with a higher proportion of strokes. A recent meta-analysis showed that CABG was associated with a one-third reduction in all-cause mortality, compared with $\mathrm{PCI}$ in diabetics with multivessel disease.

We performed a cumulative analysis (Figure 1) of the included studies in that meta-analysis ${ }^{4,8,10-15}$; all-cause mortality at the longest available follow-up strongly and statistically favored CABG following the publication of FREEDOM (before FREEDOM: cumulative odds ratio [OR] 0.63, 95\% confidence interval [CI], 0.35-1.12, $P=.12$; after FREEDOM: cumulative OR $0.69,95 \% \mathrm{CI}$, $0.53-0.89, P=.005)$. After inclusion of the SYNTAX, United States Department of Veterans Affairs (VA), ${ }^{14}$ and MASS II (Medicine, Angioplasty, or Surgery Study) trial ${ }^{15}$ data, the revised point estimate was 0.62 , with a similar $\mathrm{CI}$ but greater statistical significance $(\mathrm{Z}=-3.27, P=.001)$.

Data Supplement 6 of the 2014 update $^{6}$ provides a table that identifies the trials that the Writing Committee considered when revising the guidelines; the table does not include the recently published VA randomized trial ${ }^{14}$ of PCI versus CABG in diabetes. A point to note is that the BARI 2D trial, which is included, is an indirect, nonrandomized comparison of PCI and CABG. ${ }^{16}$

No updates have been made with respect to unprotected left main disease. ${ }^{6}$ The current 2012 American guidelines ${ }^{7}$ recommend CABG (Class I, Level B) to improve survival. PCI is a reasonable alternative option (Class IIa, Level B) if the coronary anatomy is low risk (SYNTAX score $\leq 22$ ) or is an ostial or trunk lesion and the risk of surgery is high. In the subanalysis of the unprotected left main disease cohort in the SYNTAX study, no differences were found in major adverse cardiac and cerebrovascular events between CABG and PCI for low and intermediate SYNTAX scores at 5 years. ${ }^{5}$

A recent Bayesian meta-analysis of 12 studies comparing CABG with PCI in patients with unprotected left main 
Cumulative Meta-analysis of Randomized Trials Comparing CABG versus PCl (Bare-metal and Drugeluting stents)

Study name Time point

\begin{tabular}{|c|c|c|c|c|c|c|}
\hline & & Point & $\begin{array}{c}\text { Lower } \\
\text { limit }\end{array}$ & $\begin{array}{c}\text { Upper } \\
\text { limit }\end{array}$ & Z-Value & $\mathrm{p}$-Value \\
\hline ARTS I & 2005 & 0.588 & 0.238 & 1.454 & -1.150 & 0.2 \\
\hline ERACI II & 2005 & 0.681 & 0.315 & 1.471 & -0.978 & \\
\hline sos & 2008 & 0.516 & 0.267 & 0.995 & -1.976 & 0.0 \\
\hline CARDia & 2010 & 0.631 & 0.354 & 1.122 & -1.567 & 0.1 \\
\hline Freedom & 2012 & 0.689 & 0.532 & 0.892 & -2.827 & 0.0 \\
\hline SYNTAX & 2013 & 0.663 & 0.526 & 0.836 & -3.474 & 0.0 \\
\hline VA & 2013 & 0.581 & 0.415 & 0.813 & -3.165 & 0.0 \\
\hline \multirow[t]{2}{*}{ MASS II } & 2013 & 0.615 & 0.460 & 0.823 & -3.267 & 0.0 \\
\hline & & 0.615 & 0.460 & 0.823 & -3.267 & \\
\hline
\end{tabular}

Cumulative odds ratio $(95 \% \mathrm{Cl})$

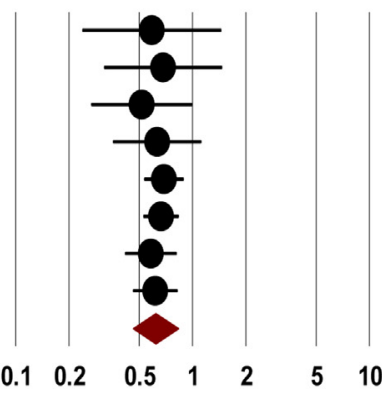

Favours CABG Favours $\mathrm{PCl}$

FIGURE 1. Cumulative meta-analysis of all-cause mortality at the longest reported follow-up. Studies used were the Arterial Revascularization Therapies Study (ARTS I) ${ }^{10}$ the Argentine Randomized Study: Coronary Angioplasty with Stenting Versus Coronary Bypass Surgery in Patients with Multiple-Vessel Disease $(E R A C I I I),{ }^{11}$ Stent or Surgery $(S O S),{ }^{12}$ Coronary Artery Revascularization in Diabetes $($ CARDia $),{ }^{13}$ Future REvascularization Evaluation in Patients with Diabetes Mellitus: Optimal Management of Multi-vessel Disease (FREEDOM) ${ }^{4}$ SYNergy Between Percutaneous Coronary Intervention With TAXus and Cardiac Surgery $\left(\right.$ SYNTAX),${ }^{8}$ United States Department of Veterans Affairs (VA), ${ }^{14}$ and the Medicine, Angioplasty, or Surgery Study II (MASS $I I) .{ }^{15} C A B G$, Coronary artery bypass grafting surgery; $P C I$, percutaneous coronary intervention; $C I$, confidence interval.

disease reported that at 1 year, mortality rates were similar following CABG and $\mathrm{PCI}^{17}$; in addition, Data Supplement 4 of the 2014 update $^{6}$ shows a large number of studies with equivalent survival after $\mathrm{CABG}$ and PCI. One of the current limitations of the comparative unprotected left main disease revascularization investigations is that only a small number of studies assess long-term outcomes; current trials are underway, including the EXCEL (Evaluation of Xience Prime versus Coronary Artery Bypass Surgery for Effectiveness of Left Main Revascularization) trial, to assess longitudinal 5year outcomes in unprotected left main disease patients. ${ }^{18}$

Finally, one of the main messages from the SYNTAX study is that the severity of coronary disease is an important factor in PCI, whereas patient comorbidities may be more relevant for CABG. ${ }^{5,19}$ Incorporation of clinical and anatomic risk scores, along with patient preference, is essential in the therapeutic decision making for any individual patient. ${ }^{2,20}$ Therefore, having a heart team consisting of at least one general cardiologist, an interventional cardiologist, and a cardiac surgeon is essential to provide the very best, patientcentered, evidence-based recommendation. ${ }^{2,20}$ These updates reflect the dynamic paradigm of coronary revascularization techniques and highlight the importance and influence of robust scientific studies.

\section{References}

1. Epstein AJ, Polsky D, Yang F, Yang L, Groeneveld PW. Coronary revascularization trends in the United States, 2001-2008. JAMA. 2011;305: 1769-76.

2. Deb S, Wijeysundera HC, Ko DT, Tsubota H, Hill S, Fremes SE. Coronary artery bypass graft surgery vs percutaneous interventions in coronary revascularization: a systematic review. JAMA. 2013;310:2086-95.
3. Bari investigators. The final 10-year follow-up results from the BARI randomized trial. J Am Coll Cardiol. 2007;49:1600-6.

4. Farkouh ME, Domanski M, Sleeper LA, Siami FS, Dangas G, Mack M, et al. Strategies for multivessel revascularization in patients with diabetes. $N$ Engl J Med. 2012;367:2375-84

5. Mohr FW, Morice MC, Kappetein AP, Feldman TE, Stahle E, Colombo A, et al. Coronary artery bypass graft surgery versus percutaneous coronary intervention in patients with three-vessel disease and left main coronary disease: 5year follow-up of the randomised, clinical SYNTAX trial. Lancet. 2013;381: 629-38.

6. Fihn SD, Blankenship JC, Alexander KP, Bittl JA, Byrne JG, Fletcher BJ, et al. 2014 ACC/AHA/AATS/PCNA/SCAI/STS Focused Update of the Guideline for the Diagnosis and Management of Patients With Stable Ischemic Heart Disease: A Report of the American College of Cardiology/American Heart Association Task Force on Practice Guidelines, and the American Association for Thoracic Surgery, Preventive Cardiovascular Nurses Association, Society for Cardiovascular Angiography and Interventions, and Society of Thoracic Surgeons. Circulation. 2014;130:1749-67.

7. Fihn SD, Gardin JM, Abrams J, Berra K, Blankenship JC, Dallas AP, et al. 2012 ACCF/AHA/ACP/AATS/PCNA/SCAI/STS guideline for the diagnosis and management of patients with stable ischemic heart disease: a report of the American College of Cardiology Foundation/American Heart Association task force on practice guidelines, and the American College of Physicians, American Association for Thoracic Surgery, Preventive Cardiovascular Nurses Association, Society for Cardiovascular Angiography and Interventions, and Society of Thoracic Surgeons. Circulation. 2012;126:e354-471.

8. Kappetein AP, Head SJ, Morice MC, Banning AP, Serruys PW, Mohr FW, et al. Treatment of complex coronary artery disease in patients with diabetes: 5-year results comparing outcomes of bypass surgery and percutaneous coronary intervention in the SYNTAX trial. Eur J Cardiothorac Surg. 2013;43:1006-13.

9. Verma S, Farkouh ME, Yanagawa B, Fitchett DH, Ahsan MR, Ruel M, et al. Comparison of coronary artery bypass surgery and percutaneous coronary intervention in patients with diabetes: a meta-analysis of randomised controlled trials. Lancet Diabet Endocrinol. 2013;1:317-28.

10. Serruys PW, Ong AT, van Herwerden LA, Sousa JE, Jatene A, Bonnier JJ, et al. Five-year outcomes after coronary stenting versus bypass surgery for the treatment of multivessel disease: the final analysis of the Arterial Revascularization Therapies Study (ARTS) randomized trial. J Am Coll Cardiol. 2005;46:575-81.

11. Rodriguez AE, Baldi J, Fernandez Pereira C, Navia J, Rodriguez Alemparte M, Delacasa A, et al. Five-year follow-up of the Argentine randomized trial of 
coronary angioplasty with stenting versus coronary bypass surgery in patients with multiple vessel disease (ERACI II). J Am Coll Cardiol. 2005;46:582-8.

12. Booth J, Clayton T, Pepper J, Nugara F, Flather M, Sigwart U, et al. Randomized, controlled trial of coronary artery bypass surgery versus percutaneous coronary intervention in patients with multivessel coronary artery disease: six-year follow-up from the Stent or Surgery Trial (SoS). Circulation. 2008; 118:381-8.

13. Kapur A, Hall RJ, Malik IS, Qureshi AC, Butts J, de Belder M, et al. Randomized comparison of percutaneous coronary intervention with coronary artery bypass grafting in diabetic patients. 1-year results of the CARDia (Coronary Artery Revascularization in Diabetes) trial. J Am Coll Cardiol. 2010;55:432-40.

14. Kamalesh M, Sharp TG, Tang XC, Shunk K, Ward HB, Walsh J, et al. Percutaneous coronary intervention versus coronary bypass surgery in United States veterans with diabetes. J Am Coll Cardiol. 2013;61:808-16.

15. Lima EG, Hueb W, Garcia RM, Pereira AC, Soares PR, Favarato D, et al. Impact of diabetes on 10-year outcomes of patients with multivessel coronary artery disease in the Medicine, Angioplasty, or Surgery Study II (MASS II) trial. Am Heart J. 2013;166:250-7.

16. Chaitman BR, Hardison RM, Adler D, Gebhart S, Grogan M, Ocampo S, et al. The Bypass Angioplasty Revascularization Investigation 2 Diabetes randomized trial of different treatment strategies in type 2 diabetes mellitus with stable ischemic heart disease: impact of treatment strategy on cardiac mortality and myocardial infarction. Circulation. 2009;120:2529-40.

17. Bittl JA, He Y, Jacobs AK, Yancy CW, Normand SL. American College of Cardiology Foundation/American Heart Association Task Force on Practice G. Bayesian methods affirm the use of percutaneous coronary intervention to improve survival in patients with unprotected left main coronary artery disease. Circulation. 2013;127:2177-85

18. National Institutes of Health. EXCEL clinical trial. Available at: https:// clinicaltrials.gov/ct2/show/NCT01205776?term $=$ excel + clinical + trial\&rank $=1$. Accessed November 27, 2014

19. Morice MC, Serruys PW, Kappetein AP, Feldman TE, Stahle E, Colombo A, et al. Outcomes in patients with de novo left main disease treated with either percutaneous coronary intervention using paclitaxel-eluting stents or coronary artery bypass graft treatment in the SYNergy Between Percutaneous Coronary Intervention with TAXus and Cardiac Surgery (SYNTAX) trial. Circulation. 2010;121:2645-53

20. Head SJ, Kaul S, Mack MJ, Serruys PW, Taggart DP, Holmes DR Jr, et al. The rationale for heart team decision-making for patients with stable, complex coronary artery disease. Eur Heart J. 2013;34:2510-8. 